\title{
PEMBUATAN GENERATOR SINKRON UNTUK PEMBANGKIT LISTRIK TENAGA MIKROHIDRO DARI MAGNET MOTOR BEKAS DI DESA KEMUMU BENGKULU UTARA
}

\section{MANUFACTURING OF GENERATOR SINCRON BY USING THE RECYCLE OF MAGNET MOTORCYCLE FOR MICRO HYDRO POWER PLANT IN THE KEMUMU VILLAGE NORTH BENGKULU}

\author{
Oleh: \\ Hendra $^{1)}$, Muhammad Syaiful ${ }^{2)}$, dan Anizar Indriani ${ }^{3)}$ \\ 1) Program Studi Teknik Mesin Fakutlas Teknik Universitas Bengkulu \\ 2) Jurusan Teknologi Ilmu Pertanian Fakultas Pertanian Universitas Bengkulu \\ ${ }^{3)}$ Program Studi Teknik Elektro Fakutlas Teknik Universitas Bengkulu \\ h7f1973@yahoo.com
}

\begin{abstract}
Community empowerment in improving the knowledge to make a generator by using the recycle of magnet of the motorcycle is part of a community service-based research through training manufacture of generators. This generator can be used to change of mechanical energy into the electrical energy. Where as the mechanical energy is obtained from the turbine screw. This training method contains material about the introduction of the generator and proceed with the process of manufacture of generators by using recycle of motorcycle magnet coil manner. Generators are made tested with the 3 phase of motors as early movers to get the magnitude of the voltage output of the generator. After the output voltage is obtained then followed by using the turbinesscrew, windmills or other propulsion to drive the generators. Magnet motor that is made into a generator consists of several magnetic poles are 6, 8 and 12 poles. Mechanism of the generator is expected to help the community in generating electrical energy as a power source of the electrical power and that does not depend anymore on electricity company such as PLN for lighting, drying, cooling and others. Through this training, the potential flow of a river or irrigation water in the village of Keтumu can be utilized by the villagers to meet the need for electrical energy. Where electrical energy can be used to increasing the economy value and daily life of rural communities Kemumu. Of the training conducted, it was found that the generator capable of producing an electrical voltage of 106 volts with the rotation drive of screw turbines is $876 \mathrm{rpm}$ and 12 pole magnet generator. The generator with an output voltage of 6 obtained by 78, 4 Volt with one load of 15-watt incandescent light bulb. And using four load of 15-watt incandescent light bulbs obtained 58,8 Volt output voltage by using a magnetic generator 8 poles. From these results can be concluded that the generators by using the recycle magnet of motorcycle by the community can generate an electric voltage.
\end{abstract}

Keywords: Generator, PLTMH, Electrical Energy, Magnet Motor, Turbin Screw 


\section{PENDAHULUAN}

Ketergantungan energi listrik dari PLN yang sangat besar menyebabkan masyarakat harus menerima segala kondisi yang ada seperti pemadaman listrik yang tiba-tiba atau bergilir, kerusakan komponen elektronik oleh tegangan listrik yang tidak stabil ataupun daerah yang masih belum terjangkau oleh listrik. Keluhan akan fenomena di atas selalu ada setiap waktu, dimana PLN selalu berusaha agar tidak terjadi pemadaman ataumenjaga agar tegangan listrik tidak turun. Hal ini sulit dihindari terutama pada daerah yang memiliki kontur alam dengan kondisi hutan, perkebunan atau pepohonan pada jalur lintasan kabel listrik, kondisi iklim dengan kekuatan angin yang kuat (daerah pegunungan dan pantai).

Kondisi ini sangat banyak ditemukan di Indonesia seperti daerah Bengkulu, dimana daerah ini banyak memiliki perkebunan, hutan dan berada di daerah pesisir pantai. Pemadaman listrik di daerah Bengkulu sangat sering terjadi terutama pada akhir pekan dimana penyebabnya adanya pemadaman bergilir akibat pasokan untuk mesin penggerak turbin yang kurang, adanya pohon atau dahan tumbuhan yang mengganggu kabel-kabel listrik dan angin kencang yang menyebabkan terjadinya hubungan pendek dan lain sebagainya. Selain itu kondisi daerah yang juga jauh dari sentral listrik PLN memnyebabkan pasokan ke daerah tersebut berkurang sehingga listrik padam atau tegangan turun.

Untuk menanggulangi hal ini, pemerintah daerah dan PLN mencoba melakukan pengembangan sistem pembangkit listrik dengan mencari sumber energi alternatif untuk penggerak sistem pembangkit listrik seperti penggunaan solar sel, turbin screw, kincir angin dan lainnya. Dengan melihat potensi yang ada pada daerah masing-masing seperti daerah pantai Kota Bengkulu yang memiliki kekuatan angin besar dapat digunakan pembangkit listrik tenaga angin, Desa Kemumu yang memiliki sumber air sungai dan irigasi yang besar dapat digunakan untuk pembangkit listrik tenaga air (Kumar and David, 2012) (Dietzel, 1990) (Damastuti, 1997) (Muller, 2009) (Rorres, 2000) (Havendry, 2009) (Subekti, 2010) (Gudukeya and Madanhire, 2013) (Hendra, 2014) (Hendra, 2013) dan potensi energi surya yang cukup tinggi untuk pembangkit listrik tenaga surya. Selama ini pembangkit listrik di Bengkulu diperoleh dari sumber tenaga minyak bumi dan batubara.

Melihat situasi ini maka dalam pelatihan ini difokuskan pada pemanfaatan sumber energi listrik dari tenaga air (PLTMH) dengan membuat generator sinkron dari magnet sepeda motor bekas dan sumber penggerak awal dari motor 3 Phasa dan turbin screw. Generator ini dibuat dan digunakan pada turbin screw dengan menggunakan potensi aliran air sungai atau irigasi di Desa Kemumu Bengkulu Utara. Dimana aliran sungai atau irigasinya memiliki head yang tidak terlalu tinggi dan debit yang cukup besar. Potensi ini dapat digunakan untuk pembangkit listrik tenaga air (mikrohidro) skala kecil menggunakan turbin screw. Selain itu mesin pembangkit listrik tenaga mikrohidro (Dietzel, 1990) (Damastuti, 1997) lain juga dapat digunakan seperti turbin Pelton, Francis dan Kaplan. Penggunaan turbin ini bagi masyarakat agak sulit karena memerlukan daerah 
yang luas, perawatan yang kontinu, ongkos pembuatan yang mahal dan kadang merusak lingkungan.

Dalam pengabdian masyarakat berbasis riset ini akan diadakan pelatihan kepada masyarakat untuk membuat generator dan pembangkit listrik yang murah dan mudah dibuat dengan memanfaatkan peralatan bekas atau sisa. Pada pelatihan ini masyarakat dibimbing untuk memanfaatkan komponen magnet motor bekas menjadi generator agar dapat digunakan pada pembangkit listrik tenaga mikrohidro dengan penggerak turbin screw.

Tegangan listrik yang kurang stabil dan pemadaman yang sering terjadi disebabkan oleh terganggunya sistem distribusi jaringan listrik seperti cuaca yang kurang baik (angin ribut), pohon tumbang dan sumber energi penggerak generator listrik yang makin berkurang akibat kelangkaan dan mahalnya harga bahan bakar minyak bumi. Hal ini menyebabkan masyarakat mengalami kerugian seperti kerusakan alat-alat elektronik, terganggunya proses pengolahan hasil panen, banyaknya kriminalitas di malam hari karena suasana yang gelap dan lainnya.

Permasalahan yang sering timbul ini sangat mengganggu sistem perekonomian dan kehidupan masyarakat di daerah karena semua peralatan elektornik, proses pengolahan hasil panen dan lainnya sangat bergantung pada energi listrik dari PLN. Untuk itu diperlukan suatu cara dalam menanggulangi hal ini dengan membuat alat dan teknologi tepat guna yang murah dan mudah dioperasikan oleh masyarakat seperti pemanfaatan magnet sepeda motor bekas untuk generator pada pembangkit listrik tenaga mikrohidro menggunakan turbin screw atau untuk generator pembangkit lainnya.

Pemanfaatan generator dalam menunjang kehidupan manusia sudah banyak digunakan seperti pada pembangkit listrik, otomotif dan bidang lainnya. Generator berfungsi untuk meubah energi mekanik menjadi energi listrik. Dimana energi mekanik terdiri atas energi kinetik dan energi potensial. Energi kinetik diperoleh dari gerakan yang terjadi pada generator dimana gerakan ini diperoleh dari energi potensial dari aliran air yang ada.

Keluaran dari generator berupa energi listrik dapat dalam bentuk arus bolak balik (AC) dan searah (DC) tergantung pada konstruksi generator yang digunakan. Untuk generator AC, tegangan yang dihasilkan dapat langsung didapatkan dan untuk generator DC tegangan yang dihasilkan disearahkan dengan komutator. Selain tegangan yang dihasilkan, posisi kumparan jangkar dan stator juga berbeda yaitu untuk generator AC, kumparan jangkar terletak pada bagian stator dan medan kumparan medan pada bagian rotor. Sementara untuk generator DC, kumparan jangkar berada pada rotor dan kumparan magnet pada stator.

Prinsip kerja generator adalah pada kumparan akan terjadi induksi jika sebuah kumparan berada dalam medan magnet yang selalu berubah. Generator terdiri atas mesin sinkron dan unsikron dimana mesin sikron bekerja pada kondisi steady dengan kecepatan dan frekuensi konstan. Keluaran mesin sinkron adalah arus bolak balik dan dikenal dengan 
alternator (Zuhal, 1998). Generator sinkron akan menghasilkan kecepatan sinkron yang diperoleh dari putaran rotor yang sama dengan putaran medan magnet stator. Generator sinkron terdiri dari generator arus bolak balik 1 dan 3 fasa.

Gambar 1 menunjukan bentuk generator arus bolak balik 1 dan 3 fasa. Untuk mengetahui mekanisme kerja dan performance generator sinkron harus diketahui konstruksi komponen utama dan pendukung serta prinsip kerja dari generator.Konstruksi generator sinkron meliputi stator yang terdiri atas rangka, inti, slot dan gigi, kumparan, rotor yang berisi slip ring, kumparan dan prime mover. Fungsi stator adalah untuk dudukan penerima induksi magnet dari rotor. Gambar 2 memperlihatkan inti dan alur stator tempat kumparan jangkar. Rotor berfungsi untuk menghasilkan tegangan dan diinduksikan ke stator. Jenis rotor pada generator adalah rotor kutub sepatu dan kutub dengan celah udara. Rotor kutub sepatu digerakan oleh turbin dengan putaran rendah dan rotor kutub celah udara dengan putaran tinggi. Dalam pengabdian ini menggunakan rotor kutub sepatu untuk putaran rendah.
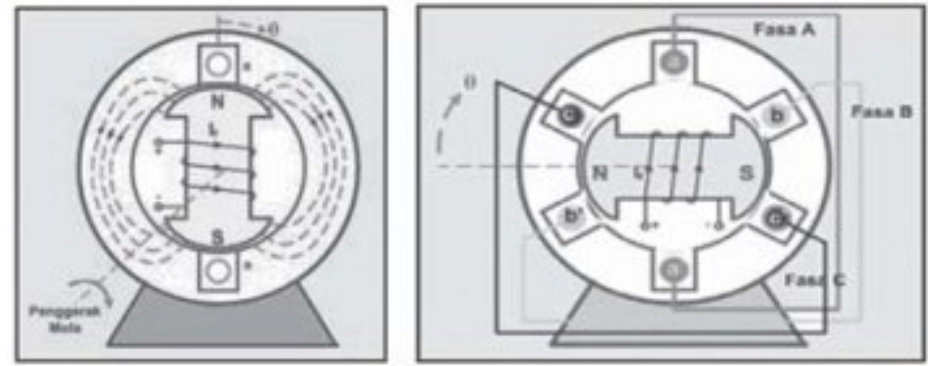

Gambar 1. (a) Diagram Generator AC Satu Fasa Dua Kutub (Zuhal, 1998)

(b) Diagram Generator AC Tiga Fasa Dua Kutub (Zuhal, 1998)

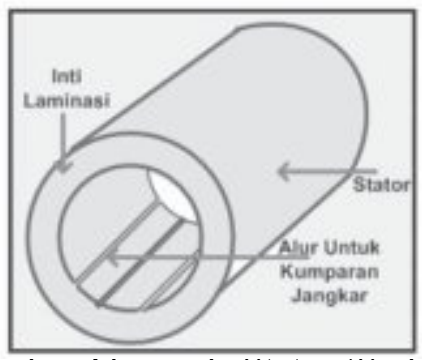

Gambar 2. Inti Stator dan Alur pada Stator (Sudırham, 2012)

Untuk penelitian generator sudah banyak dilakukan dengan menggunakan media penggerak seperti turbin, kincir dan lainnya dimana penelitian itu ada yang mengkaji untuk putaran tinggi dan rendah, pengaruh posisi magnet dan lainnya. Untuk putaran tinggi, digunakan penggerak dari turbin yang memiliki gearbox untuk meningkatkan putaran yang dihasilkan oleh turbin. Sementara untuk putaran rendah dapat dilihat pada komponen penggerak kincir air dimana pada sistem penggerak ini hanya digunakan untuk sistem gerak dengan putaran rendah. Pemanfaatan generator untuk putaran rendah masih banyak kendala dan kekurangan seperti tegangan yang dihasilkan rendah. Makanya dalam penelitian yang sudah dilakukan pada skim penelitian unggulan perguruan tinggi tahun 
2014 dilakukan pembuatan generator dengan memanfaatkan kumparan dan motor magnet sepeda motor bekas dimana telah menghasilkan tegangan listrik pada sistem pembangkit listrik tenaga mikrohidro dengan putaran rendah yaitu pada pembangkit listrik tenaga mikrohidro dengan menggunakan turbin screw (Hendra, 2014) (Hendra, 2013).

Kelanjutan dari penerapan penelitian tersebut dilakukan alih teknologi kepada masyarakat melalui pelatihan pengenalan generator dan aplikasinya pada komponen mesin pembangkit listrik tenaga mikrohidro, pelatihan pembuatan dan melilit kumparan untuk generator dan pengujian hasil generator yang dibuat. Generator ini memiliki beberapa komponen seperti rotor dan stator dimana rotor mengandung komponen magnet yang terdiri atas beberapa kutub dan stator berisi lilitan kumparan. Jumlah lilitan kumparan dan magnet sangat mempengaruhi kinerja dan prestasi dari generator.

Pada pengabdian ini generator yang digunakan adalah generator sinkron magnet permanen yang dirancang dan dibuat dengan berupa generator satu fasa tipe fluks radial dengan memanfaatkan magnet permanen dan stator motor bekas. Generator ini terdiri atas komponen kumparan stator dan magnet rotor. Kumparan stator terbuat dari stator motor bekas yang dimodifikasi untuk digunakan pada putaran rendah. Magnet rotor terletak pada bagian luar stator dimana pada rotor ini terdapat beberapa elemen magnet yang jumlahnya sesuai dengan jumlah kutub pada kumparan stator.

Dalam pengabdian ini menggunakan magnet motor dan kumparan yang terdiri dari 6, 8 dan 12 kutub dan dimanfaatkan untuk pembangkit listrik tenaga mikrohidro. Pemanfaatan mikrohidro diawali oleh masalah yang sering muncul terutama di daerah terpencil akan pasokan listrik. Dimana daerah tersebut memiliki potensi seperti air sungai dan irigasi. Potensi ini dapat digunakan untuk menghasilkan pembangkit listrik dengan kapasitas yang kurang dari $100 \mathrm{~kW}$ dengan menggunakan mikrohidro.

Pembangkit listrik tenaga mikrohidro (PLTMH) (Kumar and David, 2012) (Damastuti, 1997) (Gudukeya and Madanhire, 2013) memanfaatkan air sebagai sumber penggeraknya dimana prinsip kerja PLTMH adalah meubah energi potensial dan kinetik menjadi mekanik hingga menghasilkan energi listrik. PLTMH memiliki tiga komponen utama yaitu air, turbin (Hendra, 2014) (Hendra, 2013) dan generator (Fifi dan Joke, 2012). Air sebagai penggerak sudu atau screw turbin. Besarnya gerakan untuk mendorong sudu tergantung kepada jumlah debit dan ketinggian jatuh air (menghasilkan energi potensial). Debit aliran merupakan banyaknya jumlah air yang mengalir per satuan waktu (liter/dt) dan ketinggian jatuh air (head) adalah besarnya jarak antara titik jatuh air dengan turbin (Hendra, 2014). Energi potensial dan gerak diubah menjadi energi mekanik dan diteruskan oleh poros (Hendra, 2014) (Fifi dan Joke, 2012) ke generator. Pada generator energi mekanik diubah menjadi energi listrik. Besarnya pengaruh debit dan ketinggian jatuh air terhadap daya keluaran pada generator dapat dilihat pada Tabel 1.

PLTMH memiliki beberapa keuntungan yaitu tidak merusak habitat yang digunakan, ramah lingkungan, memerlukan areal yang tidak terlalu luas untuk peralatan dan sistem operasinya sederhana. PLTMH sangat cocok digunakan untuk menjangkau 
ketersediaan jaringan energi listrik pada daerah yang terpencil.

PLTMH dengan pembangkit lain seperti kincir dan jenis lain memerlukan bendungan atau dam untuk mengatur aliran air untuk penggeraknya, bangunan pengambil air (intake), saluran penghantar untuk mengalirkan air dari intake, saluran pelimpah air, kolam penenang dan pipa pesat yang berfungsi untuk mengalirkan air ke turbin.

Gambar 3 menunjukan komponen mesin pada PLTMH dengan mekanisme tidak langsung dan jenis-jenis PLTMH.

Tabel 1. Hubungan Daya Keluaran dengan Debit dan Head

\begin{tabular}{cccc}
\hline $\begin{array}{c}\text { Head } \\
(\mathbf{m})\end{array}$ & $\begin{array}{c}\text { Debit aliran air } \\
\mathbf{Q}(\mathbf{l} / \mathbf{d t})\end{array}$ & $\begin{array}{c}\text { Output } \\
\text { Turbin }(\mathbf{k W})\end{array}$ & $\begin{array}{c}\text { Output } \\
\text { Generator }(\mathbf{k W})\end{array}$ \\
\hline 24 & 33.3 & 5.9 & 4.7 \\
26 & 34.6 & 6.7 & 5.3 \\
28 & 36 & 7.4 & 5.9 \\
30 & 37.2 & 8.2 & 6.6 \\
32 & 38.4 & 9.0 & 7.2 \\
34 & 39.6 & 10 & 8 \\
\hline
\end{tabular}
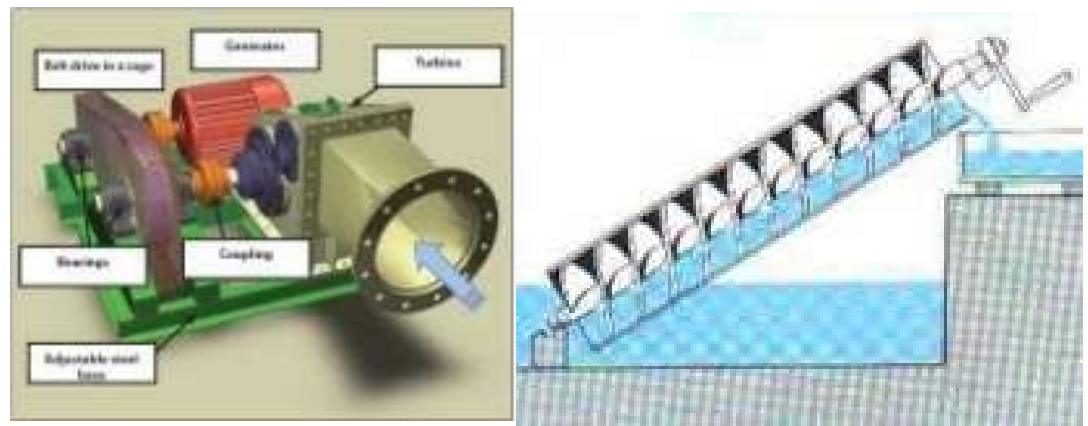

a. Komponen Mesin dan PLTMH (Rorres, 2000)

b. Screw turbin Penggerak Manual (Rorres, 2000)

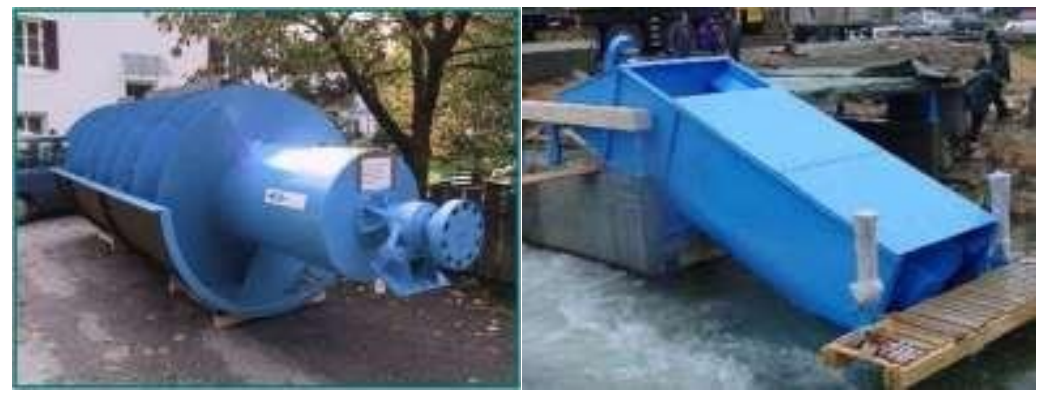

c. Type Steel trough (Havendry, 2009)

d. Type Closed compact installation (Havendry, 2009)

Gambar 3. Komponen Mesin dan PLTMH

Tujuan kegiatan pengabdian masyarakat ini adalah:

1. Memberikan pelatihan tentang komponen-komponen generator dan cara perakitannya. 
2. Pelatihan pemasangan kumparan pada dudukan kumparan dan pemasangan pada magnet motor generator.

Manfaat pelatihan ini adalah agar masyarakat dapat membuat generator dari magnet motor bekas untuk pembangkit listrik tenaga mikro hidro seperti menggunakan turbin screw, kincir dan lainnya.

\section{METODE PENGABDIAN}

Metode pelaksanaan pengabdian yang dilakukan adalah dengan metode pelatihan cara memanfaatkan dan membuat magnet sepeda motor bekas menjadi generator untuk pembangkit listrik tenaga mikrohidro menggunakan turbin screw. Dimana magnet sepeda motor bekas ini sudah dibuat dan digunakan dalam penelitian unggulan perguruan tinggi (BOPTN) tahun 2013 (Hendra, 2014) (Hendra, 2013).

Ada beberapa tahap pelatihan pembuatan dan perakitan generator dari magnet bekas yaitu:

1. Pelatihan pengenalan komponen mesin pembangkit listrik tenaga mikrohidro menggunakan turbin screw.

Proses pelatihannya adalah dengan menjelaskan dan memberi contoh komponen mesin pembangkit listrik tenaga mikrohidro menggunakan turbin screw yang digunakan seperti:

1. Komponen mekanik meliputi turbin screw.

2. Komponen elektrik meliputi generator yang terdiri atas magnet sepeda motor bekas dan lilitan kumparan.

3. Rangka mesin pembangkit listrik tenaga mikrohidro menggunakan turbin screw.

4. Bantalan

5. Poros.

2. Pelatihan pembuatan komponen elektrik generator dari magnet sepeda motor bekas untuk pembangkit listrik tenaga mikrohidro menggunakan turbin screw dan pengujian.

Prosedur pelatihan ini meliputi:

1. Pemilihan magnet sepeda motor bekas berdasarkan variasi jumlah magnet dan lilitan kumparan.

2. Metode dan cara pemasangan kumparan pada dudukan lilitan kumparan (melilit).

3. Pemilihan dan penggunaan dimensi kawat lilitan kumparan yang berbeda.

4. Pengujian generator (magnet dan lilitan magnet) tanpa beban dengan variasi jumlah lilitan.

5. Pengujian generator (magnet dan lilitan magnet) dengan menggunakan beban dengan variasi jumlah lilitan. 
6. Pengujian generator (magnet dan lilitan magnet) tanpa beban dengan variasi dimensi lilitan.

7. Pengujian generator (magnet dan lilitan magnet) dengan menggunakan beban dengan variasi dimensi lilitan

3. Pelatihan pemeliharaan magnet sepeda motor bekas sebagai generator pembangkit listrik tenaga mikrohido

Prosedur pelatihan yaitu:

1. Pelatihan pemeliharaan komponen-komponen generator dan mesin pembangkit listrik tenaga mikrohidro.

2. Pelatihan pengecekan kondisi atau keadaan lilitan kumparan magnet motor (generator).

3. Pelatihan perbaikan komponen generator dan metode pembongkaran dan pemasangan komponen generator.
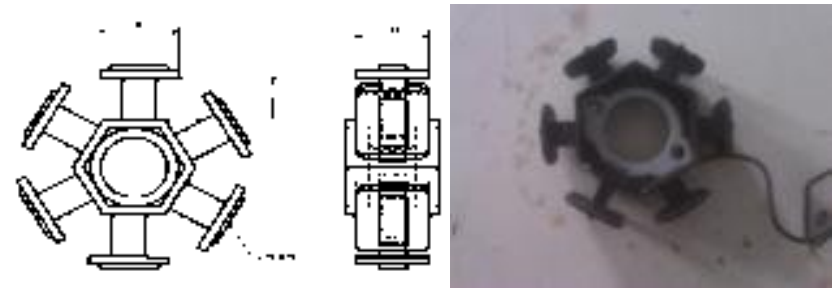

a. Dimensi Kumparan Kawat/Lilitan Magnet Sepeda motor bekas

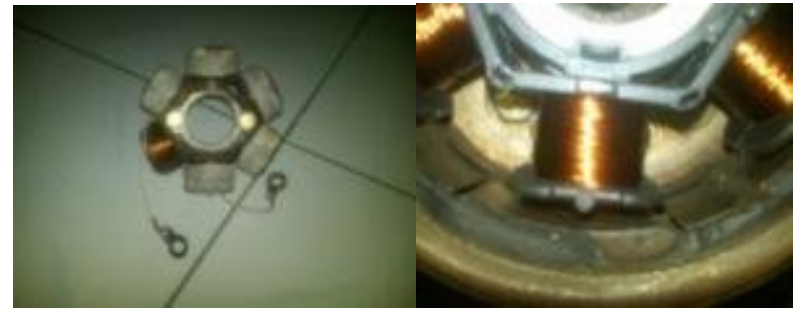

b. Magnet Rotor dan Gabungan dengan Kawat Kumparan

Gambar 4. Magnet Sepeda motor bekas untuk Generator Pembangkit Listrik Tenaga Mikrohidro

Gambar 4 menunjukkan rancangan generator yang terdiri dari magnet sepeda motor bekas dan lilitan kumparannya. Gambar 5 menunjukkan elemen kumparan dengan dimensi yang berbeda dan pengujian untuk generator tanpa beban. Jenis magnet sepeda motor bekas yang akan dimanfaatkan dalam pelatihan ini dapat dilihat pada Gambar 6, dimana pada Gambar 6 terlihat jenis-jenis magnet dan dudukan kumparan lilitan.

Proses Pengujian tegangan output generator (Hendra, 2014) (Hendra, 2013) (Fifi dan Joke, 2012) dari magnet sepeda motor bekas yaitu:

1. Pengujian generator tanpa beban 
Pengujian generator tanpa beban bertujuan untuk mengetahui besar tegangan keluaran generator pada saat tanpa beban. Langkah-langkah pengujian meliputi:

a) Generator diputar pada kecepatan nominal (n).

b) Tidak ada beban yang terhubung pada terminal generator.

c) Catat nilai tegangan terminal generator.

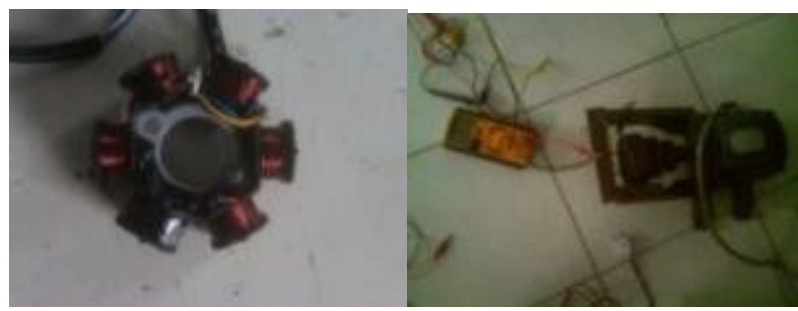

Gambar 5. Elemen Kumparan dengan Dimensi Berbeda dan Pengujian Tanpa Beban

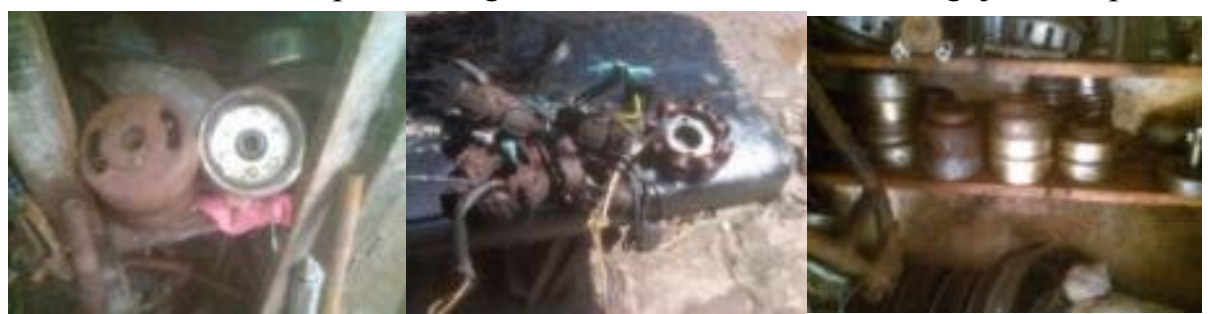

Gambar 6. Magnet Sepeda Motor Bekas dan Dudukan Lilitan Kumparan

2. Pengujian berbeban

Pengujian berbeban bertujuan untuk mengetahui besar tegangan dan arus keluaran generator dengan menggunakan beban seperti lampu pijar 15 Watt.

\section{HASIL DAN PEMBAHASAN}

\section{Hasil Pengabdian Masyarakat}

Peserta yang mengikuti pelatihan ini adalah 20 peserta dimana hasil yang diperoleh adalah peserta mampu membuat generator dengan hasil tegangan luarannya adalah 106,9 Volt pada generator dengan magnet motor 12 kutub. Peserta yang hadir dapat dilihat pada Gambar 7 dan Gambar 8. Pada Gambar 7 terlihat sambutan dari Kepala Desa dan pemaparan pemanfaatan magnet sepeda motor bekas untuk generator pada PLTMH. Gambar 8 menunjukan proses pembuatan generator pada magnet sepeda motor bekas yang diawali dengan proses pelatihan melilit kumparan dan magnet.
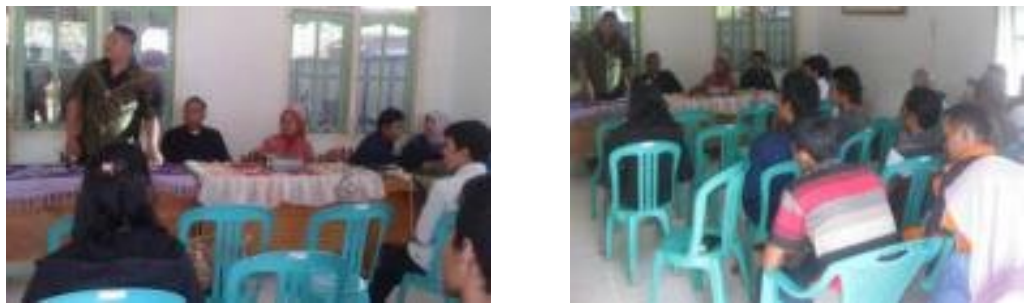

a. Kata sambutan Bapak Kepala Desa sebelum pelatihan 

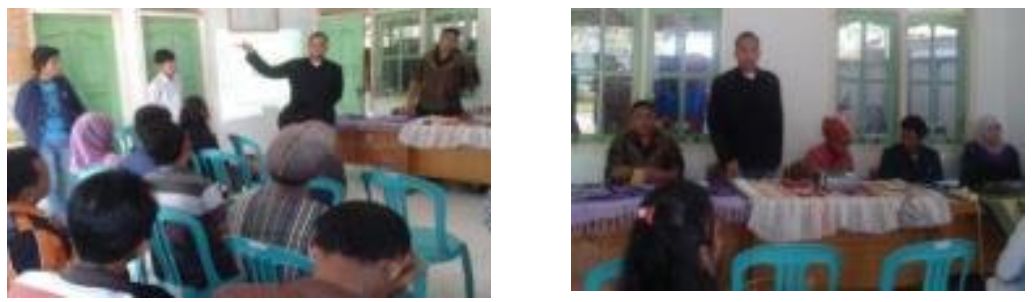

b. Peserta pelatihan dan Pemaparan pemanfaatan dan pembuatan Generator Gambar 7. Kegiatan Pelatihan Proses Pemanfaatan Magnet Sepeda Motor Bekas untuk Generator pada PLTMH

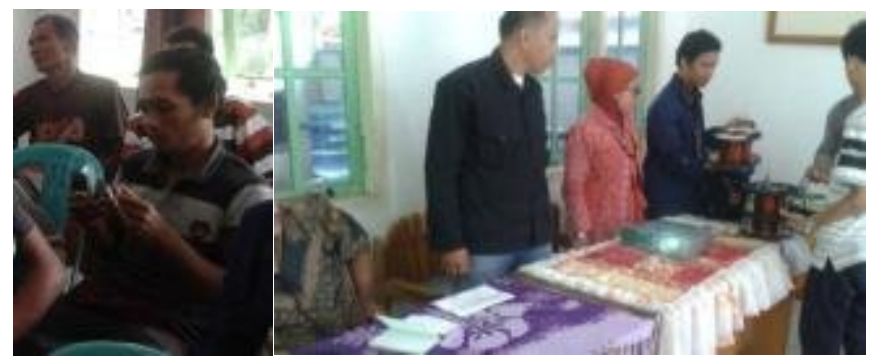

a. Pengenalan Magnet Motor Sepeda Motor Bekas
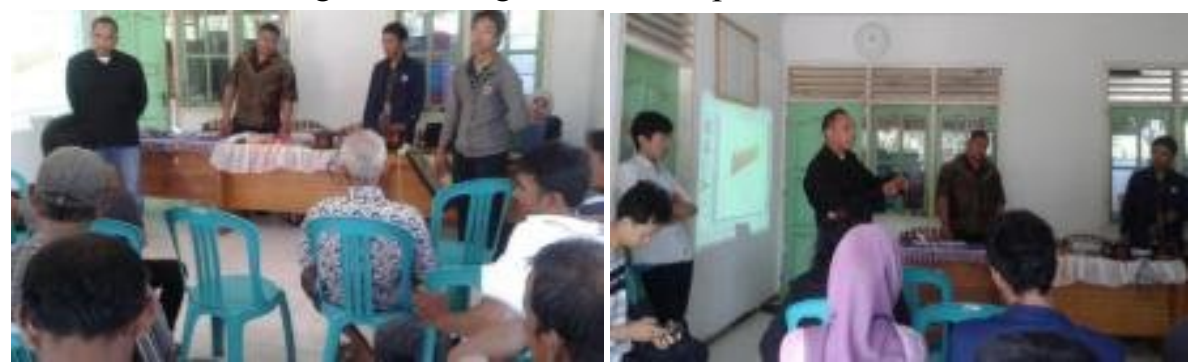

b. Tanya Jawab Tentang Pemanfaatan Magnet Sepeda Motor Bekas

Gambar 8. Proses Pembuatan Generator dan Diskusi Manfaat Lainnya

\section{Hasil Pengujian Magnet Sepeda Motor Bekas}

Hasil pembuatan generator dari magnet motor bekas dan dari pengujian generator yang dilakukan diperoleh tegangan keluaran dari generator dengan magnet motor 6 kutubtanpa pembebanan sebesar 74.4 Volt pada putaran $842 \mathrm{rpm}$ sementara untuk putaran $920 \mathrm{rpm}$ sebesar 79.4 Volt dan hasil pengujiannya dapat dilihat pada Tabel 2. Untuk pengujian dengan menggunakan beban lampu pijar sebesar 15 watt diperoleh tegangan keluaran generator dengan magnet 6 kutub sebesar 78.4 Volt pada putaran $880 \mathrm{rpm}$. Hasil pengujian generator dengan menggunakan beban lampu pijar dapat dilihat pada Tabel 3.

Untuk hasil pengujian generator dengan jumlah kutub yang lain menggunakan beban lampu pijar 15 watt dan penggerak generator dari turbin screw seperti generator dengan 12 kutub magnet rotor dapat dilihat pada Tabel 4. Dimana pada Tabel 4 terlihat bahwa tegangan keluaran dari generator dengan magnet rotor 12 kutub adalah sebesar 105.9 Volt 
pada putaran $876 \mathrm{rpm}$ dan. Untuk pengujian generator berbeban pada putaran $876 \mathrm{rpm}$ dengan 4 bola lampu pijar dan generator dengan magnet rotor 8 kutub diperoleh tegangan sebesar 58.8 Volt seperti dapat dilihat pada Tabel 5.

Tabel 2. Hasil Pengujian Generator dengan Tanpa Beban

\begin{tabular}{ccc}
\hline \multirow{2}{*}{ No } & Putaran (rpm) & Tegangan Keluaran \\
\cline { 3 - 3 } & & Magnet Rotor 6 Kutub (Volt) \\
\hline 1 & 842 & 74.4 \\
& 920 & 79.4 \\
\hline
\end{tabular}

Tabel 3. Hasil Pengujian Generator dengan Beban Lampu Pijar 15 Watt

\begin{tabular}{ccc}
\hline \multirow{2}{*}{ No } & Putaran (rpm) & Tegangan Keluaran \\
\cline { 3 - 3 } & 880 & Magnet Rotor 6 Kutub (Volt) \\
\hline 1 & 88.4 \\
\hline
\end{tabular}

Tabel 4. Hasil Pengujian Generator Berbeban 1 Bola Lampu dengan Turbin screw

\begin{tabular}{|c|c|c|c|}
\hline \multirow[b]{2}{*}{ No } & \multirow{2}{*}{$\begin{array}{c}\text { Putaran dengan beban } 1 \\
\text { bola lampu pijar } 15 \text { watt } \\
(\mathrm{rpm})\end{array}$} & \multicolumn{2}{|c|}{ Tegangan (Volt) } \\
\hline & & $\begin{array}{c}\text { Magnet Rotor } 6 \\
\text { Kutub }\end{array}$ & $\begin{array}{c}\text { Magnet Rotor } 12 \\
\text { Kutub }\end{array}$ \\
\hline 1 & 876 & 78.4 & 105.9 \\
\hline
\end{tabular}

Tabel 5. Hasil Pengujian Generator Berbeban 4 Bola Lampu dengan Turbin screw

\begin{tabular}{ccc}
\hline \multirow{2}{*}{ No } & $\begin{array}{c}\text { Putaran dengan beban } 4 \text { buah bola } \\
\text { lampu pijar 15 watt (rpm) }\end{array}$ & Tegangan Keluaran \\
\cline { 3 - 3 } & 876 & Magnet Rotor 8 Kutub (Volt) \\
\hline 1 & & 58.8 \\
\hline
\end{tabular}

\section{Pembahasan}

Dari hasil pelatihan pemanfaatan magnet sepeda motor bekas untuk generator pada PLTMH menunjukan respon positif dari masyarakat dan adanya keseriusan dalam mengikuti pelatihan ini. Hal ini disebabkan oleh penggunan generator sangat besar manfaatnya bagi kehidupan masyarakat terutama untuk membantu proses pengolahan hasil pertanian atau perkebunan bagi masyarakat Desa Kemumu. Dari pengujian generator yang dilakukan baik dengan beban ataupun tanpa beban diperoleh hasil bahwa generator ini dapat digunakan untuk membangkitkan energi listrik (untuk lampu pijar dan lainnya). Tegangan keluaran dari generator ini dapat juga digunakan untuk tenaga listrik bagi proses pengolahan hasil kebun atau pertanian masyarakat seperti untuk proses pengeringan hasil panen, pengolahan dan pengepakan hasil panen dan lain sebagainya. 


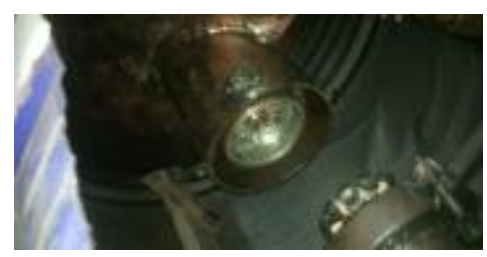

a. Dudukan Magnet Stator 6 Kutub dan Lilitan Kumparan pada Turbin screw

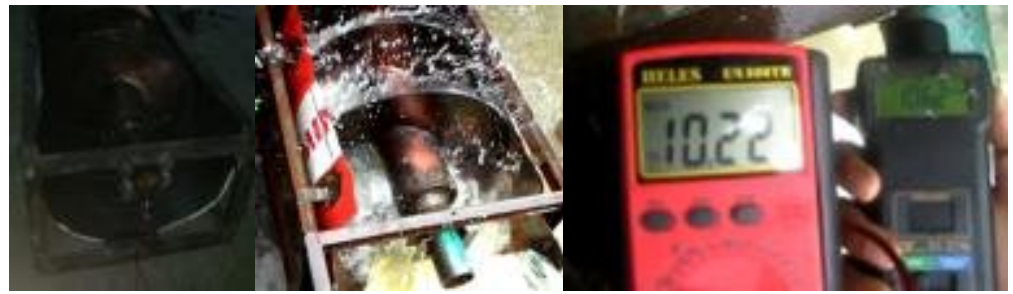

b. Tempat Pemasangan Magnet Rotor 6 Kutub dan Lilitan Kumparannya dan pengukuran tegangan untuk magnet rotor 6 kutub pada putaran 106 rpm

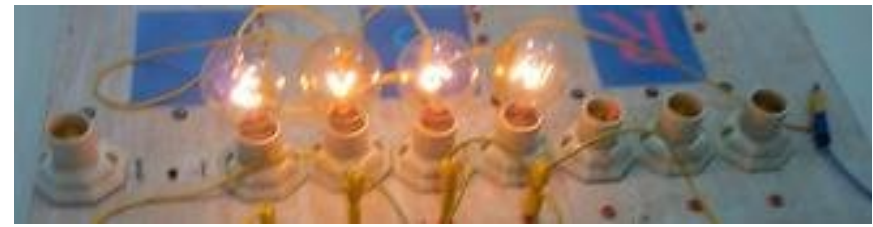

c. Pengujian Generator dengan Beban 4 Lampu Pijar Menggunakan Magnet Rotor 8 Kutub

Gambar 9. Pengujian Generator pada Turbin screw

Dari hasil pegujian generator menggunakan sumber penggerak dari motor 3 phasa dan turbin screw terlihat bahwa dimensi, jumlah lilitan dan kutub akan mempengaruhi tegangan keluaran dari generator. Semakin banyak jumlah kutub dan lilitan serta dimensin dudukan litlitan kumparan (stator) maka tegangan keluaran yang dihasilkan akan semakin besar. Hal ini dapat dilihat pada Tabel 4, dimana pada pengujian ini terlihat pada generator dengan magnet rotor 12 kutub memiliki nilai tegangan keluaran lebih tinggi dibanding dengan nilai tegangan keluaran generator dengan magnet rotor 6 dan 8 kutub. Hal ini disebabkan oleh dimensi dari dudukan lilitan kumparan magnet, jumlah kutub magnet rotor dan lilitannya lebih besar dibanding dengan magnet 6 dan 8 kutub. Ini menunjukan bahwa dimensin dan jumlah kutub mempengaruhi tegangan keluaran dari generator.

Untuk pengujian dengan menggunakan turbin screw terlihat bahwa pengaruh senter dari sumbu putar turbin screw mempengaruhi prestasi kerja dari generator dimana posisi sumbu turbin screw yang tidak center menyebabkan putaran kerja rendah dan adanya kontak yang besar antara magnet rotor dan spul penghubung antara lilitan kumparan dengan magnet. Ini menyebabkan penurunan prestasi kerja turbin screw, menimbulkan keausan dan kerusakan pada magnet rotor serta mengakibatkan losses tegangan menjadi 
besar padasaat pengujian. Selain itu juga dapat menimbulkan kerusakan pada magnet dan lilitan kumparan dimana lilitan akibat kontak yang tejadi bisa menjadi putus.

\section{KESIMPULAN DAN SARAN}

\section{Kesimpulan}

Dari pengabdian masyarakat yang dilakukan diperoleh kesimpulan sebagai berikut:

a. Generator yang dibuat ulang dari magnet motor bekas dapat menghasilkan tegangan keluaran sebesar 79.4 Volt pada putaran $920 \mathrm{rpm}$ untuk pengujian generator tanpa beban dengan magnet rotor 6 kutub.

b. Untuk pengujian generator dengan beban lampu pijar 15 watt diperoleh tegangan keluaran sebesar 105,9 Volt pada putaran $876 \mathrm{rpm}$ untuk generator dengan magnet rotor 12 kutub sementara untuk magnet rotor 6 dan 8 kutub menghasilkan tegangan keluaran sebesar 78.4 dan 58,8 Volt.

c. Dari pelatihan yang dilakukan terlihat antusias masyarakat dalam mengikuti pelatihan dan diakhir kegiatan masayarakat meminta untuk dapat melakukan pelatihan ini secara kontinu dan juga untuk penerapan yang lain untuk penggerak generator. Dan aplikasinya untuk membantu sistem pengolahan hasil panen masyarakat.

\section{Saran}

Dari pengabdian yang sudah dilakukan terlihat antusias masyarakat dalam mengikuti kegiatan ini. Untuk mendapatkan hasil yang lebih baik pada pelatihan ini, ketepatan waktu pelatihan dengan kondisi masyarakat yang bekerja setiap hari harus diperhatikan. Karena waktu kerja masyarakat yang dimulai dari pagi hingga sore hari akan terganggu aktifitasnya jika tidak ada kesesuaian waktu dengan masyarakat sekitar.

\section{DAFTAR PUSTAKA}

Damastuti, A. P., 1997, Pembangkit Listrik Tenaga Mikrohidro, WACANA, No. 8/ MeiJuni.

Dietzel, Fritz, 1990, Turbin, Pompa dan Kompresor, Erlangga, Jakarta.

Fifi Hesty Sholihah dan Joke Pratilastiarso, 2010, Rancang Bangun Prototipe Pembangkit Listrik Tenaga Mikrohidro (PLTMH), ITS, Surabaya.

Gudukeya, L. and Madanhire, I., 2013, Efficiency Improvement of Pelton Wheel and Cross

Flow Turbines in Micro-Hydro Power Plants: Case Study, International Journal of Engineering and Computer Science ISSN: 2319-7242, Vol. 2 Issue 2, February 2013, PP. 416-432.

Havendry, A., 2009, Perancangan dan Realisasi Model Prototipe Turbin Air Type Screw (ArchimedeanTurbine) untuk Pembangkit Listrik Tenaga Mikrohidro dengan Head 
Rendah di Indonesia, Teknik A, 2009, Vol.2, No. 31, Tahun XVI, Hal.1-7.

Hendra, Anizar, I., 2013, Rancang Bangun dan Pembuatan Model Sistem Pembangkit Listrik Tenaga Mikrohidro dengan Metode Elemen hingga Berdasarkan Posisi Dan Bentuk Sudu Screw Turbin, Laporan Penelitian Unggulan Perguruan Tinggi BOPTN Universitas Bengkulu.

Hendra, Anizar, I., 2014, Manufacture of screw turbine and placement of the generator in the screw turbine shaft used for small-scale of micro hydro electrical generating, Prosiding Seminar Internasional, 2014 International Conference On Mechanical Design, Manufacture And Automation Engineering, Destech publications, Inc, January 11-12, 2014 Phuket Thailand, www.mdmae.org, Destech Publications www.destechpub.com.

Kumar, R. K and David Ian, 2012, Hydro Power Generation From Domestic Water Supply System and Development of Dynamic Flow Modelling, International Journal and Electronics Engineering Research (IJEEER), ISSN 2250=155X, Vol. 2, Issue 3 Sept 2012, 94-105.

Muller, G., 2009, Simplified Theory of Archimedean Screws, Journal of Hydraulic Research, Vol. 47, No. 5 (2009), pp. 666-669, doi:10.3826/jhr.2009.3475.

Rorres, C., 2000, The Turn of The Screw: Optimal Design of An Archimedes Screw, Journal of Hidraulic Engineering, January 2000, pp. 72-80.

Subekti, R., A., 2010, Survey Potensi Pembangkit Listrik Tenaga Mikrohidro di Kuta Malaka Kabupaten Aceh Besar Provinsi Nanggroe Aceh Darussalam, Journal of Mechatronics, Electrical Power and Vehicular Technology, Vol. 01, N0.1, 2010, ISSN. 2087-3379.

Sudirham, Sudaryatno, 2012, Analisis Rangkaian Listrik, Kanayakan D-30, Bandung.

Zuhal, 1998, Dasar Teknik Tenaga Listrik dan Elektronika Daya, PT. Rineka Cipta, Jakarta. 